\title{
Seropositividad al virus de encefalitis artritis caprina (CAE) y maedy visna (VM) en ovinos y caprinos de explotaciones semi- intensivas y extensivas del estado Lara, Venezuela
}

\author{
Seropositivity to caprine artritis encephalitis (CAE) virus and visna maedi (VM) in \\ sheep and goats from semi-intensive and extensive farms in Lara state, Venezuela
Raúl Rojas', Francisco Aldana1, Luis Barroeta', Caribay Chirinos ${ }^{1}$, Yvenioski Gamarra $^{1}$, Rafael Pérez ${ }^{1}$, Francisco Vargas ${ }^{2,3}$

\section{Resumen}

\begin{abstract}
El presente trabajo determinó la presencia de seropositividad al Lentivirosis Artritis Encefalitis Caprina (CAE) y Maedi-Visna (MV) en ovinos. Se seleccionaron al azar 260 caprinos y 30 ovinos de ganadería extensiva provenientes de cinco sectores, y 205 caprinos y 81 ovinos de ganadería semi-intensiva provenientes de cinco sectores, en ambos casos del estado Lara, Venezuela. Se realizó una encuesta epidemiológica y evaluación clínica a cada animal y se tomaron muestras de sangre para el análisis serológico por la técnica de ELISA competitivo. La seropositividad general fue de $6.25 \%$. En las ganaderías extensivas se encontraron tres caprinos $(1.46 \%)$ y tres ovinos $(3.70 \%)$ seropositivos y en las ganaderías semi-intensivas 30 caprinos resultaron positivos (11.54\%) y ningún ovino. La mayoría de los animales positivos eran cabras adultas de 23 años, a excepción de cabritos de 1 mes de edad. De los animales seropositivos, 8 cabras
\end{abstract}

\footnotetext{
${ }^{1}$ Decanato de Ciencias Veterinarias, Universidad Centroccidental Lisandro Alvarado (UACLA), Barquisimeto, Venezuela

${ }^{2}$ Facultad de Medicina Veterinaria y Zootecnia, Universidad Antonio Nariño (UAN), Bogotá, Colombia

${ }^{3}$ E-mail.vargasfrancisco@uan.edu.co
}

Recibido: 12 de mayo de 2020

Aceptado para publicación: 25 de septiembre de 2021

Publicado: 27 de octubre de 2021

CLos autores. Este artículo es publicado por la Rev Inv Vet Perú de la Facultad de Medicina Veterinaria, Universidad Nacional Mayor de San Marcos. Este es un artículo de acceso abierto, distribuido bajo los términos de la licencia Creative Commons Atribución 4.0 Internacional (CC BY 4.0) [https:// creativecommons.org/licenses/by/4.0/deed.es] que permite el uso, distribución y reproducción en cualquier medio, siempre que la obra original sea debidamente citada de su fuente original 
(22.2\%) presentaron signos clínicos y el resto fue asintomático. Los signos clínicos fueron artritis y mastitis crónica en cabras y sintomatología nerviosa en un cabrito. Se demuestra la circulación del virus CAE/MV en caprinos y ovinos, en especial en fincas de ganadería caprina intensiva tecnificada en Venezuela y la presencia de signos clínicos compatibles con la enfermedad.

Palabras clave: lentivirosis, CAE y MV, ovinos, caprinos, ELISA, Venezuela

\section{Abstract}

The present work aimed to determine the presence of seropositivity to Caprine Lentivirosis Arthritis Encephalitis (CAE) and Maedi-Visna (MV) in sheep. In total, 260 goats and 30 sheep from extensive farms from 5 sectors, and 205 goats and 81 sheep from semi-intensive farms from 5 sectors were randomly selected, in both cases from Lara state, Venezuela. An epidemiological survey and clinical evaluation were carried out on each animal and blood samples were taken for serological analysis by the competitive ELISA technique. The general seropositivity was $6.25 \%$. In the extensive flocks, three goats $(1.46 \%)$ and three sheep $(3.70 \%)$ were seropositive and in the semi-intensive flocks 30 goats were positive (11.54\%) and no sheep. Most of the positive animals were 2- to 3 year-old goats, except for 1 month old kid. Of the seropositive animals, eight goats $(22.2 \%)$ presented clinical signs and the rest were asymptomatic. The clinical signs were arthritis and chronic mastitis in goats and nervous symptoms in a kid. The circulation of the CAE/MV virus in goats and sheep is demonstrated, especially in farms of intensive technical goat farming in Venezuela and the presence of clinical signs compatible with the disease.

Key words: lentivirosis, CAE and MV, sheep, goats, ELISA, Venezuela

\section{INTRODUCCIÓN}

Las lentivirosis de los pequeños rumiantes son causadas por un lentivirus de la familia Retroviridae. Entre ellas, la Artritis y Encefalitis Caprina (CAE) y el virus de Maedi Visna (MV) se describen como procesos infectocontagiosos que pueden causar grandes pérdidas económicas, tanto directa como indirectamente, a los productores. El virus CAE afecta a los caprinos, de evolución clínica lenta que puede presentarse como un cuadro nervioso en cabritos de 1-4 meses de edad o como artritis, neumonías, encefalitis o mastitis en cabras adultas (Crawford y Adams, 1980; Zink et al., 1987; Clemens y Zink, 1996; Contreras y Sánchez, 2003). Por su parte, el virus MV afecta a los ovinos adultos, cau- sando disnea, por lo que también se le denomina neumonía progresiva ovina, aunque puede presentarse con cuadros clínicos nerviosos (conocidos como Visna), mastitis y artritis, presentando largo periodo de incubación y desenlace fatal (Narayan y Cork, 1985; Bulguins, 1990).

El virus de CAE-MV tiene un tropismo por las células del sistema reticuloendotelial, siendo trasportado a diferentes tejidos a través de células dendríticas macrófagos y monocitos (Contreras y Sánchez, 2003). Uno de los principales tejidos de replicación del virus es la glándula mamaria, donde se excreta en el calostro y la leche, trasmitiéndose de la madre a la cría; causando además un efecto inmunosupresivo sobre la cría (Fariñas y Zorrilla, 2002). 
Ambos virus son antigénicamente similares y producen reacciones cruzadas en pruebas serológicas y cuadros lesionales muy semejantes, por lo que muchos autores se refieren a lentivirosis en general y no en forma separada como CAE o MV (Lujan y Badiola, 2001). Por lo tanto, para el diagnóstico serológico mediante pruebas de ELISA e Inmunodifusión en gel agar (IDGA) de ambas enfermedades se utiliza el mismo antígeno concentrado de cultivos celulares infectados por virus Maedi-Visna, que contiene las dos proteínas estructurales de mayor tamaño del virus, la p 25 del núcleo viral y p125 de la envoltura viral (Lujan y Badiola, 2001).

Estas enfermedades se trasmiten solo de forma natural de manera horizontal (de un animal a otro), en especial cuando una hembra portadora del virus amamanta a su cría (Lujan y Badiola, 2001). El virus se ha detectado en el semen en animales seropositivos (Travassos et al., 1999; Martinez et al., 2005), pero es poco lo que se conoce sobre la transmisión vertical (durante la gestación) a través de la monta natural, inseminación o trasplantes de embriones (Adams et al., 1983; Trigo, 1991).

Las explotaciones caprinas y ovinas en Venezuela, y en especial en el estado Lara, ha tomado gran impulso con la introducción de razas mejoradas (Armas et al., 2006). Por otro lado, si bien se encuentran explotaciones caprinas con sintomatología compatible con la enfermedad CAE, son pocos los estudios de seropositividad reportados y en muchos casos las pruebas serológicas arrojan resultados falsos negativos en animales con signos evidentes (Nieto y Armas, 2017). En los municipios del estado Lara existe una alta probabilidad de propagación de estas enfermedades por la costumbre de los productores de intercambiar animales (en especial padrotes) y por las prácticas de pastoreo extensivo. Ante esto, el objetivo de esta investigación fue determinar la presencia de anticuerpos contra el virus de CAE y MV mediante serología (ELISA) en los rebaños caprinos y ovinos criados en sistemas extensivos y semi-intensivos en los municipios Iribarren, Jimenez y Torres del estado Lara, así como la presencia de signos clínicos asociados a estas enfermedades.

\section{Materiales y Métodos}

\section{Población y Muestra}

El cálculo del tamaño muestral se realizó con la formula indicada por el Centro Panamericano de Zoonosis, la Organización Panamericana de la Salud (OPS) y la Organización Mundial de la Salud (OMS) para el estudio de detección de enfermedades crónicas (Thrusfield, 1990). Dado que no existe información en el área de estudio para CAEV y MV, se asumió una prevalencia de $50 \%$, con un nivel de confianza del $95 \%$, considerando el máximo tamaño de muestra. En tal sentido, se estimó una muestra de 400 animales. En la práctica y para los fines del estudio, se trabajó con 290 animales de ganadería semi-intensiva (260 caprinos y 30 ovinos) y 286 animales de ganadería extensiva (205 caprinos y 81 ovinos), dando un total de 576 animales muestreados (Cuadro 1).

Para el caso de la ganadería extensiva, el estudio se realizó en seis caseríos de la parroquia Espinosa de los Monteros del municipio Torres (Cascajales, Chirico, Las Palmitas, Bocare y Agua Salada) del estado Lara. Todos los caseríos son colindantes y cercanos a la autopista El Rodeo-Carora. Se hizo especial énfasis en las explotaciones tradicionales caprinas, ovinas y mixtas a libre pastoreo (en un aprisco colectivo durante la noche y al pastoreo libre durante el día).

Para el estudio en la ganadería semiintensiva, se tomaron los sectores Tintorero, Paso Real y Maguace del municipio Jiménez y Juan de Villa Rosa y Rio Claro del municipio Iribarren (Estado Lara). En estas explotaciones, los animales son mantenidos en corrales y reciben pasto de corte y alimento 
concentrado u otro suplemento alimenticio y salen a pastorear en el día en potreros muy pequeños cercanos a la casa. Los ovinos presentes en estos rebaños, son grupo pequeños que se mantienen junto con los rebaños caprinos.

\section{Criterios de Inclusión}

Las explotaciones fueron seleccionadas de manera sistemática y aleatoria a partir de los listados contentivos de predios caprinos por sector, los cuales fueron obtenidos en las instituciones del Estado. Así mismo, se obtuvieron datos del total de las explotaciones, el total de la población y sus grupos etarios. A cada predio se le asignó un número, para que tuvieran la misma oportunidad de entrar en el muestreo. Se trabajó con animales de los dos sexos y de todas las edades en forma aleatoria.

\section{Recolección de Datos}

Los animales fueron identificados con aretes plásticos. Se les realizó un examen clínico general para detectar signos característicos de CAE como de MV. Los datos fueron recogidos en un instrumento tipo encuesta epidemiológica.

\section{Procesamiento de Muestras}

Se tomaron muestras de sangre de la vena yugular en tubos Vacutainer ${ }^{\circledR}$ estériles sin anticoagulante. Se dejó coagular las muestras a temperatura ambiente y luego fueron centrifugadas para la obtención del suero. Los sueros fueron trasvasados a tubos Eppendorf y almacenados en congelación hasta su análisis.

El análisis de los sueros se hizo con un ELISA competitivo de CAE y MV (Chekit $\mathrm{CAE} / \mathrm{MV}$; Boehring $\left.{ }^{\circledR}\right)$. El estuche contiene microplacas con antígeno inactivado y un conjugado anti-IgG de cabra o borrego marcado con peroxidasa. Se siguieron las instrucciones del fabricante. Las muestras fueron procesadas en el Laboratorio de la Unidad de Ovinos y Caprinos (UNICO) del Decanato de Ciencias Veterinarias de la Universidad Centroccidental Lisandro Alvarado (UCLA).

\section{Resultados y Discusión}

Se analizaron 576 sueros y se encontraron 36 positivos al virus de Encefalitis Artritis Caprina (CAE) y Maedi-Visna (MV) por la prueba de ELISA, lo que representa una seropositividad general de $6.25 \%$ (Cuadro 1). Esto difiere del estudio de Salazar et al. (2006), quienes analizaron sueros de la población caprina del estado Falcón, encontrando resultados negativos en todas las muestras; sin embargo, la seroprevalencia encontrada fue similar al $6.3 \%$ reportado en el estudio de Mogollón et al. (1988), en el departamento de Santander, Colombia.

La seropositividad total a lentivirus de pequeños rumiantes obtenida indica un nivel bajo. Reportes de Brasil (Pinheiro et al., 2001) y Argentina (Robles et al., 2003) muestran prevalencias menores a $10 \%$, mientras que en España se ha reportado seroprevalencias entre 1.3 y $55.2 \%$, dependiendo de las localidades de muestreo (Contreras y Sánchez, 2003).

\section{Ganadería Extensiva}

En las ganaderías de caprinos y ovinos de ganadería extensiva en el municipio Torres se determinó una seroprevalencia de $2.1 \%$ (6/286. Para el caso de los caprinos, la seropositividad fue de $1.46 \%$ (3/205) en tanto que para los ovinos fue de $3.70 \%(3 / 81)$ (Cuadro 1).

Los caprinos seropositivos eran cabras adultas (2-3 años), y presentaban artritis y mastitis crónica, ambos signos clínicos compatibles con la enfermedad en caprinos (no se observaron cuadros respiratorios, nerviosos o reproductivos). En el caso de los ovinos 
Cuadro 1. Porcentaje de animales seropositivos a ELISA para el virus de la Artritis y Encefalitis Caprina (CAE) y el virus de Maedi Visna (MV) en ovinos y caprinos de explotaciones semi-intensivas y extensivas del estado Lara, Venezuela

\begin{tabular}{llccc}
\hline \multirow{2}{*}{ Tipo de explotación } & \multirow{2}{*}{ Especie } & Muestras (n) & \multicolumn{3}{c}{ Positivas } \\
\cline { 3 - 5 } Extensiva & Caprina & 205 & $\mathrm{n}$ & $\%$ \\
& Ovina & 81 & 3 & 1.46 \\
\cline { 3 - 5 } Subtotal & & 286 & 3 & 3.70 \\
\hline \multirow{2}{*}{ Semi-intensiva } & \multirow{2}{*}{ Caprina } & 260 & 3 & 2.10 \\
& Ovina & 30 & 0 & 11.54 \\
\cline { 3 - 5 } & & 290 & 30 & 0 \\
\hline \multirow{2}{*}{ Sotal } & & 576 & 36 & 10.34 \\
\hline
\end{tabular}

seropositivos fueron también hembras adultas (2-3 años), pero no presentaban signos clínicos compatible con la enfermedad.

Se podría esperar mayores porcentajes de seropositividad con base a resultados de otras investigaciones (Cutlip et al., 1992; Tesoro et al., 2003); sin embargo, en este tipo de sistema de producción a libre pastoreo los animales tienen menor contacto entre sí y escaso contacto con ambientes contaminados cerrados, como son los corrales, lo que reduce las posibilidades de infección y de trasmisión del virus de un animal a otro. Esto explica los bajos porcentajes de positividad observados en ganadería extensiva, tanto en ovinos como en caprinos. Sin embargo, observando los datos por sectores y por finca (Cuadro 2), se observa una circulación viral en algunas fincas y sectores muy específicos como es el caso de las fincas 1 y 3 en el sector Agua Salada y en la finca 4 del sector las Palmitas. Las demás fincas y sectores resultaron negativos, indicando la ausencia de circulación viral.

\section{Ganadería Semi-Intensiva}

Treinta de las 260 muestras de suero de caprinos criados en sistemas semi-intensivos resultaron positivos (11.54\%) (Cuadro 1). Por su parte, ninguna de las 30 muestras de ovinos colectadas en las mismas explotaciones caprinas resultó seropositiva. Estos resultados indican un nivel de positividad bajo en comparación con reportes de otros países (Adams et al., 1984), pero es relativamente mayor si se compara con el $2.10 \%$ encontrado en el presente estudio en la ganadería extensiva, lo cual concuerda con Contreras y Sánchez (2003), quienes indican un mayor riesgo de presentarse la enfermedad en las explotaciones caprinas de producción de leche con ordeño.

La mayoría de las cabras que resultaron positivas a CAE-MV no presentaron sintomatología compatible con la enfermedad y se mantuvieron asintomáticas en los rebaños, lo que concuerda con lo señalado en otros estudios (Narayan et al., 1985; Tesoro et al., 
Cuadro 2. Frecuencia porcentual por finca de seropositividad a ELISA del virus CAE/MV en caprinos y ovinos bajo un sistema de crianza extensiva en el municipio Torres del estado Lara

\begin{tabular}{cccccc}
\hline \multirow{2}{*}{ Especie } & \multirow{2}{*}{ Finca } & \multirow{2}{*}{ Sector } & \multirow{2}{*}{ Muestras $(\mathrm{n})$} & \multicolumn{3}{c}{ Positivas } \\
\cline { 4 - 6 } Caprino & 1 & Agua Salada & 20 & 1 & n \\
& 3 & Agua salada & 26 & 2 & 5.00 \\
& & & 0 & 0 \\
\cline { 4 - 6 } & Otras $^{1}$ & & 205 & 3 & 1.46 \\
\hline Subtotal & & 44 & 2 & 4.55 \\
& 1 & Agua salada & 9 & 1 & 11.11 \\
& 4 & Las Palmitas & 28 & 0 & 0 \\
\cline { 3 - 6 } & Otras $^{1}$ & & 159 & 0 & 0 \\
\hline
\end{tabular}

${ }^{1} \mathrm{El}$ resto de fincas presentaron resultados negativos a la prueba de ELISA

2003). Sin embargo, 5 de 12 animales positivos de la finca 1 presentaron artritis en alguno de sus miembros, tres de ellos eran jóvenes ( 1 mes de edad) y dos eran cabras adultas (2 años). Además, uno de los animales jóvenes presentó signos nerviosos caracterizados por ataxia y una de las cabras adultas presentó signos de mastitis crónica. Estos dos signos (artritis y mastitis) son los principales signos clínicos que se han observado en caprinos adultos en otros estudios (Cutlip et al., 1992; Tesoro et al., 2003; Bedotti et al., 2007). Asimismo, se han reportado formas nerviosas en cabritos caracterizadas por un inicio súbito de incoordinación y ataxia, que progresa a una parálisis progresiva del tren posterior e incluso tetraplejia (Contreras y Corrales, 2003).

Al analizar la información por fincas bajo crianza intensiva (Cuadro 3), se aprecia que la finca 2 presentó la mayor seropositividad (53.33\%), seguida de la finca 1 $(41.38 \%)$, y la finca $3(17.14 \%)$. Las fincas 1 y 2 son explotaciones intensivas de ganadería especializada; es decir, poseen animales de alto valor genético y razas especializa- das en producción de leche, las cuales se manejan en forma estabulada, lo cual coincide con lo indicado por Contreras y Sánchez (2003) al indicar que esta enfermedad se observa con mayor incidencia en explotaciones de estas características.

La ausencia de anticuerpos específicos para la enfermedad de Maedi Visna en los ovinos de explotaciones semi-intesivas (Cuadro 1) no puede ser considerado como concluyente de la ausencia de la enfermedad, ya que las muestras tomadas no son representativas de la población ovina de los municipios Iribarren y Jiménez, pues fueron tomadas de explotaciones caprinas que tenían ovinos como actividad secundaria. La ausencia de ovinos reaccionantes en estas explotaciones puede ser explicado por el hecho de que en las mismas no está ocurriendo la trasmisión interespecie (Contreras y Sánchez, 2003), ya que estos pequeños rebaños ovinos tienen muy poco contacto directo con el rebaño caprino y se les mantiene separados, lo que dificulta la trasmisión entre ambas especies. Sin embargo, llama la atención la ocurrencia de seropositivos en ovinos de explo- 
Cuadro 3. Frecuencia porcentual por finca de seropositividad a ELISA del virus CAE/MV en caprinos y ovinos bajo un sistema de crianza intensiva en el municipio Torres del estado Lara

\begin{tabular}{cccccc}
\hline \multirow{2}{*}{ Especie } & \multirow{2}{*}{ Finca } & \multirow{2}{*}{ Sector } & Muestras $(\mathrm{n})$ & \multicolumn{3}{c}{ Positivas } \\
\cline { 3 - 6 } Caprino & 1 & Paso Real & 29 & 12 & 41.4 \\
& 2 & Maguase & 15 & 8 & 53.3 \\
& 3 & Tintorero & 35 & 6 & 17.1 \\
& 4 & Rio Claro & 50 & 1 & 2.0 \\
& 5 & Villa Rosa & 10 & 1 & 10.0 \\
& 6 & Villa Rosa & 52 & 1 & 1.9 \\
& 7 & Maguase & 20 & 1 & 5.0 \\
& 8 & Tintorero & 7 & 0 & 0.0 \\
& 9 & Maguase & 42 & 0 & 0.0 \\
\hline \multirow{6}{*}{ Ovino } & Sub-total & & 260 & 30 & 11.5 \\
& 2 & Maguase & 5 & 0 & 0 \\
& 3 & Tintorero & 5 & 0 & 0 \\
& 6 & Villa Rosa & 7 & 0 & 0 \\
& 9 & Maguase & 10 & 0 & 0 \\
\cline { 2 - 6 } & Sub-total & & 27 & 0 & 0 \\
\hline
\end{tabular}

taciones extensivas, las cuales eran explotaciones con predominancia de especie ovina y pocos caprinos, por lo que en estos casos se trataría de una circulación viral propia del virus Maedi-Visna solo en ovinos.

\section{Conclusiones}

- Se demuestra la presencia de lentivirus CAE y MV en poblaciones caprinas y ovinas con un porcentaje de seropositividad total del $6.25 \%$ del municipio Torres del estado Lara.

- Se determinó la presencia del virus de Encefalitis Artritis Caprina (CAE) en poblaciones caprinas semi-intensivas y extensivas, así como del virus Maedi Visna
(MV) en las poblaciones ovinas extensivas, más no en explotaciones semi-intensivas.

- Se evidenció la presencia de signos clínicos compatibles con la enfermedad en animales seropositivos, siendo los signos más frecuentes la artritis y mastitis crónica en cabras adultas y artritis y cuadros nerviosos en cabritos.

\section{Agradecimiento}

Los autores agradecen al Consejo de Desarrollo Científico Humanístico y Tecnológico (CDCHT) de la Universidad Centroccidental Lisandro Alvarado (UCLA) por el apoyo financiero a este proyecto de investigación. 


\section{Literatura Citada}

1. Adams DS, Klevjer-Anderson P, Carlson JL, Mc Guire TC. 1983. Transmission and control of caprine artritis-encephalitis virus. Am J Vet Res 44: 1670-1675.

2. Adams DS, Oliver RE, Ameghino E, Dematini JC, Verwoerd DJ, Houwers DJ, Waghela S, et al. 1984. Global survey of serological evidence of caprine arthritis encephalitis virus. Vet Rec 10: 493-495. doi: 10.1136/vr.115.19.493

3. Armas W, Arvelo M, Delgado A, $D^{\prime}$ Aubeterre R. 2006. El circuito caprino en los estados Lara y Falcón (Venezuela), 2001-2003: una visión estratégica. Agroalimentaria 11: 101-110.

4. Bedotti DO, Fort MC, Giménez H, Langhoff A, Garré J, Hertsommer $O$. 2007. Descripción de un caso de artritis-encefalits caprina en la provincia de La Pampa, Argentina. En: V Congreso de Especialistas en Pequeños Rumiantes y Camélidos Sudamericanos, Mendoza, Argentina.

5. Bulguins MS. 1990. Ovine progressive pneumonia, caprine artrtritis- encephalitis: and related lentiviral diseases of sheep and goats. Vet Clin North Am Food Anim Pract 6: 691-704. doi: 10.1016/s07490720(15)30841-0

6. Contreras A, Corrales J. 2003. Artritis encefalitis caprina II. OVIS 88: 11-72.

7. Contreras A, Sánchez A. 2003. Artritis encefalitis caprina I. OVIS 87: 19-31.

8. Clemens JE, Zink MC. 1996. Molecular biology and pathogenesis of animal lentivirus infections. Clin Microbiol Rev 9: 100-117. doi: 10.1128/ CMR.9.1.100

9. Crawford TB, Adams DS. 1980. Chronics arthritis in goats caused by retrovirus. Science 207: 997-999. doi: 10.1126/science.6153243

10. Cutlip RC, Lemhkuhl HD, Sacks JM, Weaver AL.1992. Prevalence of antibody to caprine arthritis-encephalitis vi- rus in goats in The United States. J Am Vet Med Assoc 200: 802-805.

11. Fariñas F, Zorrilla I. 2002. Medición del nivel de inmunodepresión resultante de la infección clínica producida por el virus de la artritis encefalitis caprina. En: Sociedad Española de ovinos y Caprinos (SEOC 2002). Valencia.

12. Lujan L, Badiola J. 2001. MaediVisna. OVIS 72: 9-93.

13. Martinez H, Ramirez H, Tórtora J, Aguilar A, Garrido G, Montaraz J. 2005. Efecto del virus de artritis encefalitis caprina en el aparato reproductor del macho caprino. Vet México 36: 159-176.

14. Mogollón Galvis JD, Moreno Hoyos O, Peña Beltrán NE, Alvarez de Agudelo DL, Cortés Castillo E, Hernández de Galvis AL. 1988. Prevalencia serológica de artritis encefalitis caprina en el departamento de Santander, Colombia. Rev ICA 23: 103-108.

15. Narayan O, Cork LC. 1985. Lentiviral diseases of sheep and goats: chronic neumonia, leukencephalomielytis and atritis. Rev Infect Dis 7: 89-98. doi: 10.1093/clinids/7.1.89

16. Nieto S, Armas W. 2017. Manejo sanitario del rebaño caprino. En: Manual de producción de caprinos y ovinos. Caracas, Venezuela: Ed Alfredo Maneiro. p 228-250.

17. Radostits OM, Gay CC, Blood DC, Hinchcliff $K W$. 2002. Medicina veterinaria. Tratado de las enfermedades del ganado bovino, ovino, porcino, caprino y equino. $9^{\circ}$ ed. Madrid, España: McGraw-Hill-Interamericana. $1454 \mathrm{p}$.

18. Pinheiro R, Gouveia A, Fernandes F. 2001. Prevalencia de infección por virus de la encefalitis artritis caprina, en Ceará, Brasil. Cienc. Rural 31(3). doi: 10.1590/S0103-84782001000300014

19. Robles CA, Layana JA, Cabrera RF, Raffo F, Cutlip R. 2003. Estudio serológico retrospectivo de Maedi (Neumonía Progresiva) en ovinos y de artritis encefalitis en caprinos de Patagonia Argentina. Rev Med Vet 84: 96-99. 
20. Salazar E, Rey-Valeiron C, Lopez J. 2006. Evaluación serológica para despistaje del virus de Artritis Encefalitis Caprina (CAE) mediante prueba de ELISA en rebaños caprinos del Estado Falcón. En: II Congreso Internacional de Ovinos y Caprinos. Barquisimeto, Venezuela.

21. Tesoro CE, Hernández GR, Martínez RA, Ramírez AH, Trujillo OMA, Kreschmer SR, et al. 2003. Detección de anticuerpos contra encefalitis artritis caprina (AEC) mediante inmunoelectrotransferencia. Vet México 34: 119-127.

22. Travassos C, Benoit C, Valas S, Da Silva A, Perrin G 1999. Caprine arthritisencephalitis vírus in semen of naturally infected bucks. Small Ruminant Res 32: 101-106.

23. Trigo FJ. 1991. La artritis encefalitis caprina. Cienc Vet 5: 49-66.

24. Thrusfield M. 1990. Epidemiologia veterinaria, estrategias y programas de combate de las enfermedades. España: Ed Acribia. p 120-140.

25. Zink M, Narayan O, Kennedy P, Clements J. 1987. Pathogenesis of visna/maedi and caprine arthritisencephalitis: new leads on the mechanism of restricted virus replication and persistent inflammation. Vet Immunopathol 15: 1671-1680. 